\title{
Effects of Cocaine on Excitation-Contraction Coupling of Aortic Smooth Muscle from the Ferret
}

\author{
Kensuke Egashira, Kathleen G. Morgan, and James P. Morgan \\ Charles A. Dana Research Institute, Harvard-Thorndike Laboratory of Beth Israel Hospital, and Department of Medicine \\ (Cardiovascular Division), Harvard Medical School, Boston, Massachusetts 02215
}

\begin{abstract}
The mechanism by which cocaine alters vascular tone is not fully understood. We determined the effects of cocaine on excitation-contraction coupling of isolated ferret aorta. Cocaine in concentrations $\leq 10^{-4} \mathrm{M}$ caused a contractile response in a dose-dependent manner. The response of control muscle was significantly larger than that in muscle from ferrets pretreated with reserpine. Cocaine-induced contraction was not affected by endothelial factors, but was significantly inhibited by prazo$\sin 10^{-7} \mathrm{M}$ pretreatment. The intracellular calcium $\left(\left[\mathrm{Ca}^{++}\right]_{1}\right)$, as measured with aequorin, rose in conjunction with cocaine-induced contraction. The degree of contraction generated by $10^{-4}$ $M$ cocaine decreased after higher concentrations of cocaine $\geq 10^{-3} \mathrm{M}$, while aequorin luminescence remained elevated above the levels before $10^{-6} \mathrm{M}$ cocaine. The dose-response relationships of norepinephrine and sympathetic nerve stimulation were enhanced by $10^{-6} \mathrm{M}$ cocaine in control muscles; this did not occur in muscles from reserpine pretreated ferrets. In conclusion, (a) cocaine in concentrations $\leq 10^{-4} \mathrm{M}$ caused vascular contraction presumably by its presynaptic action with consequent alpha-1 adrenoceptor activation and consequent $\left[\mathrm{Ca}^{++}\right]_{\mathrm{i}}$ rise; (b) high concentrations of cocaine $\geq 10^{-3} \mathrm{M}$ reduced muscle tone by decreasing the $\mathrm{Ca}^{++}$sensitivity of the contractile proteins; and $(c)$ supersensitivity to norepinephrine was mediated by cocaine's action on adrenergic nerve endings. (J. Clin. Invest. 1991. 87:1322-1328.) Key words: aequorin • intracellular calcium • excitation-contraction coupling • alpha adrenoceptor • vascular smooth muscle
\end{abstract}

\section{Introduction}

In recent years, the incidence of cardiovascular complications associated with cocaine use, including acute myocardial ischemia, have been on the rise in the United States and Europe and have become a serious medical problem (1-8). The pathophysiology of the cardiovascular toxicity after cocaine use is unknown. One of the prevailing hypotheses is that cocaine causes severe vasoconstriction of large conduit vessels with ensuing ischemia of the related organs (2-9); however the vascular actions of cocaine appear to be complex. It is generally

Address correspondence and reprint requests to Dr. James P. Morgan, Cardiovascular Division, Department of Medicine, Beth Israel Hospital, 330 Brookline Avenue, Boston, MA 02215.

Received for publication 18 December 1989 and in revised form 19 October 1990.

J. Clin. Invest.

(c) The American Society for Clinical Investigation, Inc.

$0021-9738 / 91 / 04 / 1322 / 07 \quad \$ 2.00$

Volume 87, April 1991, 1322-1328 accepted that cocaine exerts a marked sympathomimetic activity in part by inhibiting the neuronal uptake system $(10,11)$. This action would be expected to increase the tissue concentration of norepinephrine and result in alpha-adrenergically mediated vasoconstriction $(12,13)$. On the other hand, cocaine is an effective local anesthetic agent which would be expected to cause a marked relaxation of smooth muscle (9). Thus, the net vascular action of cocaine may be due to either of these two actions alone or in combination. However, the relative contributions of these actions to smooth muscle tone over the effective range of cocaine concentrations have not been systematically described. Moreover, the mechanism by which cocaine alters vascular tone has not been characterized in detail and remains controversial (12-17).

Accordingly, the purpose of this study was to determine the effects of cocaine on contractile or relaxant responses of isolated ferret aortic smooth muscle. We used ferret aorta because intracellular $\mathrm{Ca}^{++}$and contractile responses can be simultaneously measured, the former through use of the bioluminescent $\mathrm{Ca}^{++}$indicator, aequorin (18-21). The specific aims were as follows: first, we examined whether endothelial factors modify vascular responses to cocaine; second, we examined the relative contributions of cocaine's direct (i.e., a local anesthetic effect) and indirect (i.e., an effect on adrenergic nerve endings) actions on smooth muscle tone by comparing the responses of the control muscles with those of muscles from animals that had undergone reserpine pretreatment; third, we examined the mechanism of cocaine-induced contraction by the use of pharmacological receptor antagonists. We also measured intracellular $\mathrm{Ca}^{++}$mobilization in muscles that were loaded intracellularly with aequorin; and fourth, we determined factors by which cocaine potentiates the mechanical responses to exogenous and endogenous norepinephrine.

\section{Methods}

Tissue preparation. The thoracic aorta was removed from adult male ferrets under chloroform anesthesia. Circular strips $(3 \times 5-6 \mathrm{~mm})$ were prepared from the vessel according to techniques previously described (18-21), preserving perivascular tissues at room temperature in a dissecting dish filled with oxygenated PSS of the following composition (mM): $120 \mathrm{NaCl}, 5.9 \mathrm{KCl}, 11.5$ dextrose, $25 \mathrm{NaHCO}_{3}, 1.2 \mathrm{MgCl}_{2}, 1.2$ $\mathrm{NaH}_{2} \mathrm{PO}_{4}$, and $2.5 \mathrm{CaCl}_{2}$. Unless otherwise noted, the endothelium was removed by rubbing the luminal surface of the aorta. The strips were mounted in organ baths filled with $50 \mathrm{ml}$ of PSS gassed with $95 \%$ $\mathrm{O}_{2}-5 \% \mathrm{CO}_{2}\left(\mathrm{pH} 7.4\right.$ at $\left.37.5^{\circ} \mathrm{C}\right)$. One end of each preparation was fixed by a clamp and the other end was attached to a force transducer (Statham UC-2; Gould Inc., Cleveland, OH). Isometric contraction along the circular direction was recorded on a chart strip recorder (Gould Inc.; model 2200S). After equilibration for $60 \mathrm{~min}$, muscles were repeatedly contracted with $60 \mathrm{mM} \mathrm{KCl}$ and then washed with PSS at 30-min intervals. Before each contraction, the strips were progressively stretched and the process was continued until contractile re- 
sponses reached a maximal value (aequorin luminescence $\left.\left[L_{\max }\right]\right){ }^{1}$ The $\mathrm{KCl}$ solution was prepared by an equimolar replacement of sodium chloride with $\mathrm{KCl}$. After obtaining $L_{\max }, \mathrm{KCl}$-induced tension was allowed to return to basal levels before experimental protocols were initiated.

Reserpine pretreatment. Reserpine is known to deplete adrenergic nerve endings of their catecholamine content in various organs (22). Thus, reserpine $(5 \mathrm{mg} / \mathrm{kg}$, i.m.) was administered to some animals for one day before killing. Short term treatment with single doses of reserpine has been shown to produce functionally complete depletion of catecholamines from the adrenergic nerve endings of ferrets (24) and other mammals within $24 \mathrm{~h}$, although supersensitivity to norepinephrine does not become manifest for several days (23-27). As shown in the results, we found that the contractile response of muscles from reserpine pretreated ferrets to tyramine, which evokes a release of catecholamine from adrenergic nerve endings, was markedly decreased compared with muscles from control animals, while responses to norepinephrine and high $\mathrm{KCl}$ solution were not changed. These results suggest that in tissues from ferrets that have undergone short term reserpine pretreatment, catecholamine content of the perivascular nerve endings was significantly depleted while function of the postsynaptic effector sites, including alpha-adrenoceptors, may not have changed.

Transmural nerve stimulation. In selected tissues, transmural nerve stimulation was performed to evoke endogenous norepinephrine release from perivascular nerve endings. Pulses of $30 \mathrm{~V}$ and $0.5 \mathrm{~ms}$ duration at variable frequencies of $0.1,1.0,4.0$, and $8 \mathrm{~Hz}$ were delivered through two platinum-iridium electrodes $(1 \mathrm{~mm}$ in diameter) that were located in parallel with both sides of the entire length of the muscle strip. Trains of stimuli at a given frequency were continued until contractile responses reached a maximal level, and a frequency-response relation was determined.

We found in preliminary studies that contractions produced by the electrical transmural stimulation at $4 \mathrm{~Hz}$ were inhibited by nearly $100 \%$ after $0.1 \mu \mathrm{g} / \mathrm{ml}$ tetrodotoxin, and were inhibited by more than $50 \%$ after $10^{-7} \mathrm{M}$ prazosin. Therefore, these results indicate that the transmural stimulation had resulted primarily in activation of adrenergic nerve endings rather than direct stimulation of smooth muscles.

Aequorin loading and intracellular $\mathrm{Ca}^{++}$measurements. Aequorin was loaded intracellularly by a chemical procedure described previously (see references 18 and 19 for details). In prior studies, this procedure did not alter contractile responses to phenylephrine or high $\mathrm{KCl}$ solution $(20,21)$. Aequorin luminescence was monitored using a light-tight enclosure for the organ bath and photomultiplier tube (9635QA; Thorn-EMI Inc. Clinton, CT). Anodal current output from the tube (in nA) and isometric force were simultaneously recorded on a pen recorder and stored on magnetic tape with a data recorder (model 3964A; Hewlett-Packard Co., Palo Alto, CA). To estimate intracellular $\mathrm{Ca}^{++}\left(\left[\mathrm{Ca}^{++}\right]_{\mathrm{i}}\right)$ levels, aequorin luminescence was calibrated by the method of Allen and Blinks (28). At the end of each experiment, distilled water containing $10 \mathrm{mM} \mathrm{CaCl}{ }_{2}$ and $2 \%$ Triton X-100 was added to the organ bath to lyse the muscle membranes, and the light signal was recorded. $L_{\max }$ for each muscle was then calculated by multiplying the integrated light signal by the peak to integral ratio $\left(2.5\right.$ at $\left.37.5^{\circ} \mathrm{C}\right)$. After subtraction of dark current, aequorin luminescence $(L)$ at experimental points of interest was expressed as the ratio of $L / L_{\max }$. The ratio was then converted to $\left[\mathrm{Ca}^{++}\right]_{\mathrm{i}}$ using a standard calibration curve for $\log$ $L / L_{\max }$ assuming an intracellular $\left[\mathrm{Mg}^{++}\right]$of $0.5 \mathrm{mM}$ (for details see reference 28 ).

Drugs and chemicals. Cocaine $\mathrm{HCl}$ (Mallinckrodt Inc., St. Louis, MO), prazosin, atropine, norepinephrine, and tyramine (Sigma Chemical Co., St. Louis, MO) were used in these experiments.

Data analysis. Results are reported as mean \pm SEM. Unless otherwise noted, smooth muscle responses to agonists are expressed as a percentage of maximal tension evoked by $60 \mathrm{mM} \mathrm{KCl}$. The $\mathrm{EC}_{50}(\mathrm{effec}-$

1. Abbreviations used in this paper: $\left[\mathrm{Ca}^{++}\right]_{i}$, intracellular calcium; EC, effective concentration; $L$, aequorin luminescence. tive concentration of agonist required to cause $50 \%$ of the maximal contractile response to the agonist) was calculated using a computerized nonlinear equation method (29). Statistical analysis of data was performed by Student's $t$ test for paired or unpaired observations. When more than three data points or dose-response relationships were compared, analysis of variance and multiple comparison tests were used to identify differences among groups. A probability of less than 5\% was considered statistically significant.

\section{Results}

Effects of endothelial cells. Contractile responses to cocaine were examined in muscles with $(n=8)$ or without endothelial cells $(n=8)$. The functional integrity of the endothelium was tested by the presence of endothelium-dependent relaxation to carbachol in a concentration of $10^{-7} \mathrm{M}$ in muscles precontracted with norepinephrine $10^{-7} \mathrm{M} ; 62 \pm 8 \%$ relaxation and $10 \pm 4 \%$ contraction occurred in muscles with and without endothelium, respectively. As shown in Table I, a contractile response to cocaine in muscles with intact endothelium did not differ from those without endothelium. Therefore, in the following experiments, muscles without endothelial cells were used.

Effects of reserpine pretreatment. To examine the degree to which cocaine's indirect actions on adrenergic nerve terminals contributes to changes in smooth muscle tone, the effects of cocaine on control muscles were compared with those in muscles from animals pretreated for $24 \mathrm{~h}$ with reserpine (Fig. 1, Table I). There was no statistically significant difference in rest-

Table I. Smooth Muscle Tone in Control Muscles with or without Endothelial Cells and Muscles from Reserpine Pretreated Ferrets

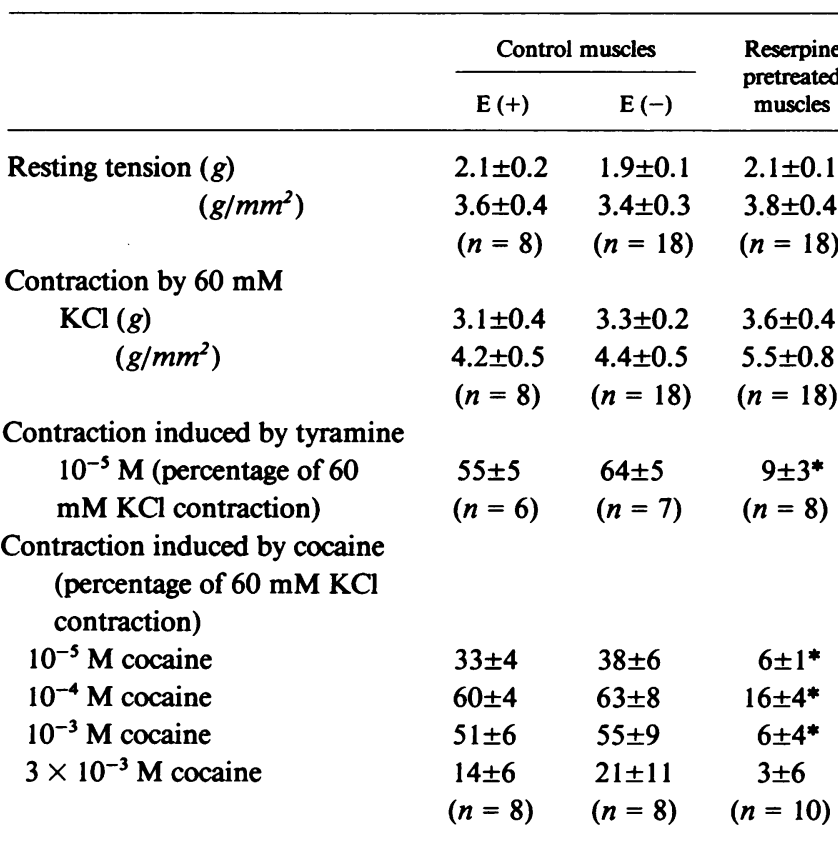

Data are presented as mean \pm SEM and were obtained from at least six animals in each group. Numbers in parentheses are the numbers of tissues tested. The force $(F)$ per cross-sectional area (CSA) was calculated as follows: $F / C S A=$ tension $\times$ tissue density $(1.05) \times$ optimal length/tissue weight. E (+), endothelial cells were preserved; $E(-)$, endothelial cells were abraded. ${ }^{*} P<0.01$ versus the control group. 


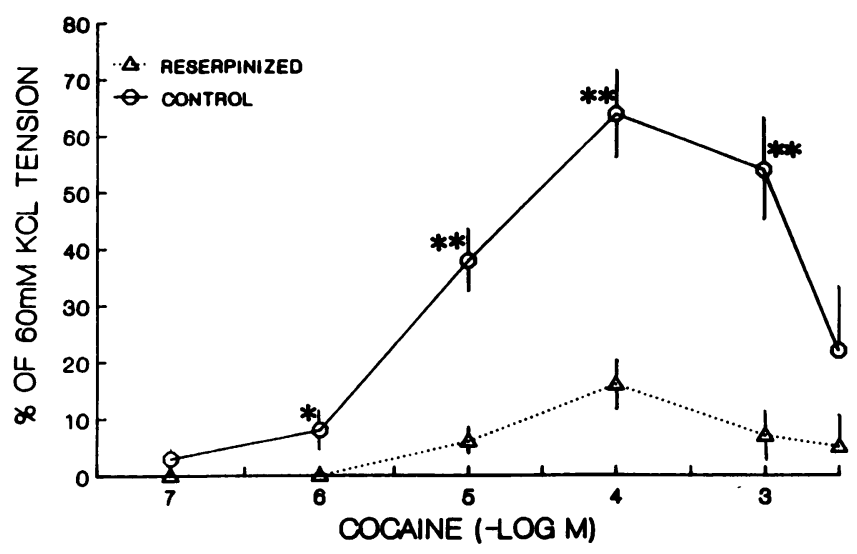

Figure 1. Dose-response relationship in control muscles (open circles) and muscles from ferrets retreated with reserpine (open triangles). Cocaine in concentrations from $10^{-7} \mathrm{M}$ to $10^{-4} \mathrm{M}$ caused dose-dependent contraction and cocaine in concentrations $\geq 10^{-3} \mathrm{M}$ produced relaxation. The constrictive responses of control muscles were significantly larger than those of muscles from reserpinized animals. $\left({ }^{*} P<0.05\right.$ and ${ }^{* *} P<0.01$ vs. reserpine pretreatment; values, mean \pm SE).

ing tension or in the amplitude of contraction produced by 60 $\mathrm{mM} \mathrm{KCl}$ in these two groups. Contractions of muscles from reserpine pretreated ferrets in response to $10^{-5} \mathrm{M}$ tyramines were significantly smaller than those from control animals ( Table I), indicating that the catecholamine content had been significantly depleted in tissues from the reserpine pretreated animals. As shown in Fig. 1, cumulative doses of cocaine produced a dual action on tension development in control muscles: dose-dependent contraction at concentrations from $10^{-7}$ to $10^{-4} \mathrm{M}$ followed by a marked relaxation at higher concentrations $\geq 10^{-3} \mathrm{M}$. The contractile response of muscles from reserpine pretreated animals was markedly decreased compared with that of control muscles.

Effects of prazosin and atropine on cocaine-induced contraction. Due to the slow and incomplete washout of high cocaine concentrations $\geq 10^{-3} \mathrm{M}$, it was difficult to obtain complete dose-response curves in experiments designed to investigate the mechanism of cocaine's action. For this reason, results shown in Table II are derived from preparations in which cocaine concentrations $\leq 10^{-4} \mathrm{M}$ were tested before and after vehicle, $10^{-7} \mathrm{M}$ prazosin (eight muscles from six ferrets) or $10^{-7}$ $M$ atropine (seven from six ferrets). Preliminary experiments in ferret aorta confirmed that prazosin and atropine in these concentrations inhibited $10^{-7} \mathrm{M}$ norepinephrine and $10^{-7} \mathrm{M}$ carbachol-induced contractions by more than $50 \%$. Table II shows that cocaine-induced contraction was significantly inhibited by prazosin while the contractile response was not affected by vehicle or atropine.

Relationship between intracellular $\mathrm{Ca}^{++}$and muscle tone. The $\left[\mathrm{Ca}^{++}\right]_{\mathrm{i}}$ change during cocaine-induced contraction was examined (Fig. 2, Table II). A typical recording of tension and $\left[\mathrm{Ca}^{++}\right]_{\mathrm{i}}$ with aequorin after the addition of $10^{-4} \mathrm{M}$ cocaine is shown in Fig. 2. Cocaine $10^{-4} \mathrm{M}$ caused a sustained contraction that reached a plateau in $16 \pm 3 \mathrm{~min}$ and $\left[\mathrm{Ca}^{++}\right]_{\mathrm{i}}$ rose slowly in conjunction with tension development. The amplitude of the contraction induced by $10^{-4} \mathrm{M}$ cocaine in aequorin loaded preparations was $55 \pm 6 \%$ of that produced by $60 \mathrm{mM} \mathrm{KCl}(n$ $=7$ ), the extent of which was comparable with that in control muscles that had not undergone the aequorin loading procedure $(63 \pm 8 \%)$. Estimated intracellular $\mathrm{Ca}^{++}$levels rose from $200 \pm 10 \mathrm{nM}$ under control conditions to $220 \pm 5 \mathrm{nM}(n=7 ; P$ $<0.05$ vs. control) after cocaine. Experiments with two successive administrations of cocaine $10^{-4} \mathrm{M}$ at an interval of $60 \mathrm{~min}$ produced the same effects on the tension and light responses $(n$ $=6$ ). As shown in Table III, both the cocaine-induced contraction and the increase in aequorin luminescence were significantly inhibited after treatment with prazosin $10^{-7} \mathrm{M}(n=7)$.

The mechanism of cocaine-induced vasorelaxation was investigated, as shown in Fig. 3. Increasing concentrations of cocaine to $10^{-3} \mathrm{M}$ and $3 \times 10^{-3} \mathrm{M}$ resulted in a marked vasorelaxation, while aequorin luminescence levels remained elevated around the level induced by $10^{-4} \mathrm{M}$ cocaine (Table IV). Beta-adrenoceptor blockade with propranolol $10^{-7} \mathrm{M}$ that was administered 2 to $3 \mathrm{~min}$ before cocaine $10^{-3} \mathrm{M}$ did not affect the relaxation induced by the high concentrations of cocaine. In preliminary studies, we found that cocaine in concentrations $\geq 10^{-3} \mathrm{M}$ inhibited the aequorin luminescence reaction in vitro. In addition, it is known that the cell membrane is permeable to local anesthetic agents like cocaine (30). For these reasons, quantitative analysis of $\left[\mathrm{Ca}^{++}\right]_{i}$ was not performed in experiments where cocaine concentrations $\geq 10^{-3} \mathrm{M}$ were used, since this might lead to significant underestimation of the actual $\left[\mathrm{Ca}^{++}\right]_{i}$ levels. It is safe to say, however, that $\left[\mathrm{Ca}^{++}\right]_{i}$ after such high concentrations of cocaine increased above the level produced by $10^{-4} \mathrm{M}$ cocaine.

Effects of cocaine on norepinephrine responses. The dose-response relationship to norepinephrine was obtained in eight muscles from six control ferrets (Fig. 4, left) and six from six ferrets that had undergone reserpine pretreatment (Fig. 4, right). In control muscles, the level of contraction induced by norepinephrine in concentrations from $10^{-8} \mathrm{M}$ to $10^{-6} \mathrm{M}$ was enhanced after $10^{-6} \mathrm{M}$ cocaine; $-\log \left(\mathrm{EC}_{50}\right)$ was significantly $(P<0.01)$ increased from $7.3 \pm 0.2$ to $7.8 \pm 0.4$ by $10^{-6} \mathrm{M}$ cocaine. This low concentration of cocaine alone produced less than $10 \%$ of the $60-\mathrm{mM} \mathrm{KCl}$ contraction (Fig. 1). Therefore, the dose-response curve of norepinephrine was shifted to the left in a parallel manner by the synergistic interaction between cocaine and norepinephrine. No such supersensitivity to nor-

Table II. Effects of Prazosin and Atropine Pretreatments on Cocaine-induced Contraction

\begin{tabular}{lcccc}
\hline & \multicolumn{5}{c}{$\begin{array}{c}\text { Concentrations of cocaine }(M) \\
\text { (percentage of } 60 \mathrm{mM} \text { KCl contraction) }\end{array}$} \\
\cline { 2 - 5 } & $10^{-7}$ & $10^{-6}$ & $10^{-5}$ & $10^{-4}$ \\
\hline $\begin{array}{l}\text { Prazosin pretreatment }(n=8) \\
\quad \text { Before }\end{array}$ & $4 \pm 1$ & $6 \pm 2$ & $39 \pm 6$ & $68 \pm 6$ \\
$\quad$ After prazosin $10^{-7} \mathrm{M}$ & 0 & 0 & $7 \pm 2^{*}$ & $18 \pm 3^{*}$ \\
Atropine pretreatment $(n=7)$ & & & & \\
$\quad$ Before & $4 \pm 0$ & $8 \pm 2$ & $35 \pm 6$ & $68 \pm 6$ \\
$\quad$ After atropine $10^{-7} \mathrm{M}$ & $2 \pm 0$ & $4 \pm 1$ & $31 \pm 6$ & $62 \pm 4$ \\
No pretreatment $(n=6)$ & & & & \\
$\quad$ Before & $2 \pm 1$ & $4 \pm 1$ & $44 \pm 6$ & $72 \pm 5$ \\
After & $1 \pm 1$ & $2 \pm 1$ & $40 \pm 5$ & $66 \pm 6$ \\
\hline
\end{tabular}

Data are presented as mean \pm SEM. ${ }^{*} P<0.01$ vs. before pretreatment. 

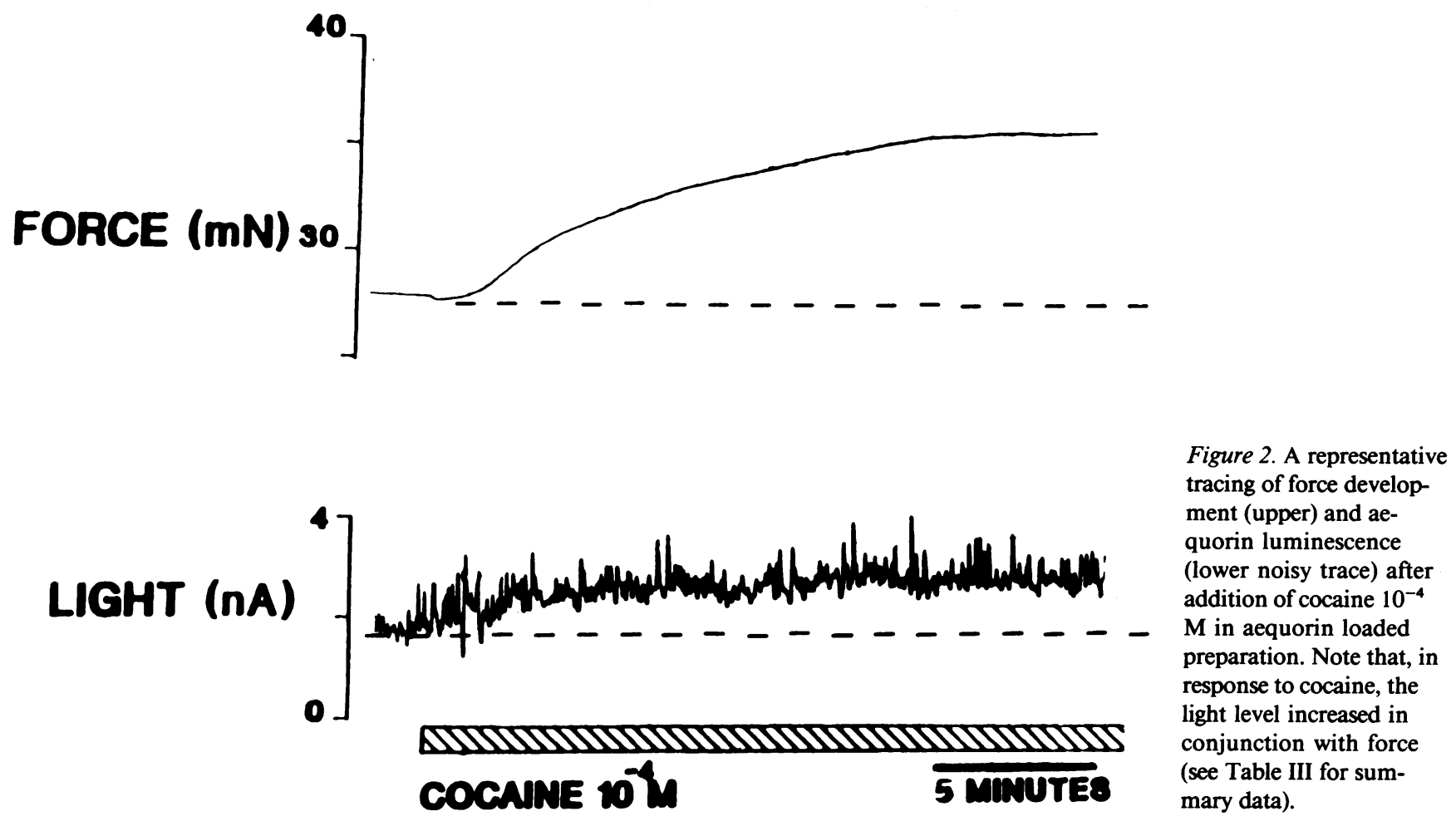

Figure 2. A representative tracing of force development (upper) and aeafter preparation. Note that, in response to cocaine, the vel increased in mary data)

epinephrine was observed in muscles from reserpine pretreated ferrets.

We also studied the frequency-response relationship of transmural nerve stimulation. As presented in Table $\mathrm{V}$, the contractile force of eight muscles from six control ferrets in response to transmural nerve stimulation increased in a frequency-dependent manner. Contractions in response to $0.1,1$, and $4 \mathrm{~Hz}$ stimulation frequencies were significantly potentiated after treatment with $10^{-6} \mathrm{M}$ cocaine, while those in response to an $8 \mathrm{~Hz}$ stimulation frequency were not significantly increased. In six muscles from six reserpine pretreated ferrets, responses to transmural nerve stimulation were not significantly changed after $10^{-6}$ cocaine.

\section{Discussion}

This study was performed because the mechanism of action of cocaine has not been fully delineated in vascular smooth mus-

Table III. Relationship of $\left[\mathrm{Ca}^{++}\right]_{i}$ and Force during Cocaine-induced Contraction in the Presence and Absence of Prazosin $(n=7)$

\begin{tabular}{lcccccc}
\hline & & & & \multicolumn{2}{c}{$\begin{array}{c}\text { Cocaine } 10^{-4} \mathrm{M} \text { after } \\
\text { pretreatment with } \\
\text { prazosin } 10^{-7} \mathrm{M}\end{array}$} \\
\cline { 2 - 3 } & Before & After & & Before & After \\
\hline Force $\left(\mathrm{g} / \mathrm{mm}^{2}\right)$ & $3.2 \pm 0.6$ & $5.1 \pm 1.4^{\ddagger}$ & & $3.0 \pm 0.6$ & $3.3 \pm 0.8$ \\
Light $(n A)$ & $1.5 \pm 0.3$ & $2.6 \pm 0.4^{*}$ & & $1.6 \pm 0.2$ & $1.7 \pm 0.3$ \\
Estimated $\left[\mathrm{Ca}^{++}\right]_{\mathrm{i}}(n M)$ & $200 \pm 10$ & $220 \pm 5^{*}$ & & $190 \pm 10$ & $200 \pm 10$
\end{tabular}

Data are presented as mean \pm SEM. ${ }^{*} P<0.05,{ }^{\ddagger} P<0.01$ vs. before cocaine. cle. The major findings of this study are as follows: first, cocaine-induced alterations in vascular tone do not differ in muscles with or without endothelial cells; second, the contractile response of control muscles to cocaine in concentrations $\leq 10^{-4} \mathrm{M}$ was significantly larger than that of muscles from reserpine pretreated ferrets in which the catecholamine content of the adrenergic nerve endings was depleted. The cocaine-induced contraction and the consequent $\left[\mathrm{Ca}^{++}\right]_{i}$ rise were inhibited after prazosin pretreatment; third, relaxation produced by more than $10^{-3} \mathrm{M}$ cocaine was not associated with a decrease in $\left[\mathrm{Ca}^{++}\right]_{i}$; and fourth, cocaine-induced supersensitivity to exogenous and endogenous norepinephrine did not occur in muscles from animals receiving short term pretreatment with reserpine.

It is well recognized that the endothelium plays an important role in the regulation of vascular smooth muscle tone (31). This study, however, indicates that the cocaine-induced contraction was not affected by the presence or absence of the endothelium, indicating that cocaine-induced contraction is not dependent upon the endothelial factor(s). This result is in agreement with a preliminary study in rabbit aortic smooth muscle (32).

Results of this study are compatible with studies in isolated rat tail arteries by Webb et al. $(12,13)$, which indicated that contraction induced by cocaine $10^{-4} \mathrm{M}$ was blocked after pretreatment with an alpha adrenergic antagonist, phentolamine, $10^{-5} \mathrm{M}$, and after chemical denervation with 6-hydroxydopamine. Analysis of contractile responses of control muscles and muscles from reserpine pretreated animals (Fig. 1, Table I) suggests that the contractile effects of cocaine in concentrations $\leq 10^{-4} \mathrm{M}$ may be due to its action on adrenergic nerve endings, whereas the relaxant effects of higher concentrations may be due to its direct actions on smooth muscle. The cocaine-induced contraction was inhibited by prazosin, but not by atropine pretreatment. Therefore, it is reasonable to propose that 


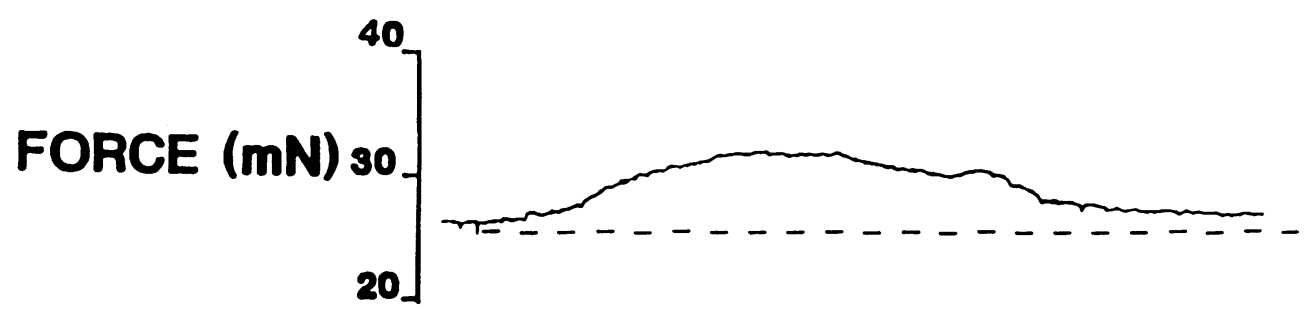

Figure 3. A representative tracing of force (upper) and aequorin lumines-

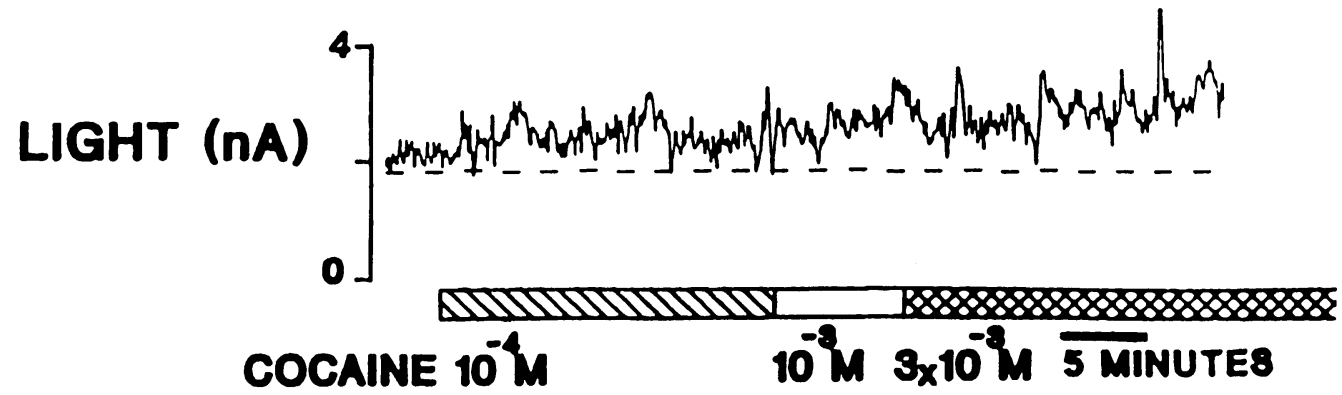
cence (lower noisy trace) during cumulative administration of cocaine from $10^{-4} \mathrm{M}$ to $3 \times 10^{-3}$ M. Administration of $10^{-3} \mathrm{M}$ and $3 \times 10^{-3} \mathrm{M}$ cocaine resulted in vasorelaxation, while the light signal remained elevated (see Table IV for summary data).

cocaine in concentrations $\leq 10^{-4} \mathrm{M}$ caused a contractile response by its presynaptic effects and subsequent alpha- 1 adrenoceptor stimulation. We speculate that endogenous norepinephrine released from adrenergic nerve endings played a major role in producing the cocaine-induced contraction, because it has been demonstrated that cocaine increases norepinephrine overflow from perfused vascular tissues and inhibits reuptake into the adrenergic nerve endings $(10,11)$. Some studies, however, suggest that cocaine-induced contraction can be produced by other mechanisms: $(a)$ cocaine increases influx of calcium across the sarcolemma by changing membrane permeability $(33,34)$; and $(b)$ cocaine produces responses by augmenting postsynaptic alpha-adrenoceptor function $(16,35$, 36). Thus, we studied $\left[\mathrm{Ca}^{++}\right]_{\mathrm{i}}$ mobilization during cocaine-induced contraction as well as the effects of the drug on norepinephrine's dose-response relationships.

$\left[\mathrm{Ca}^{++}\right]_{\mathbf{i}}$ handling during cocaine-induced changes in smooth muscle tone has not been reported to date. In this study, cocaine-induced contraction developed in parallel with the rise in $\left[\mathrm{Ca}^{++}\right]_{i}$, which was blocked by prazosin pretreat-

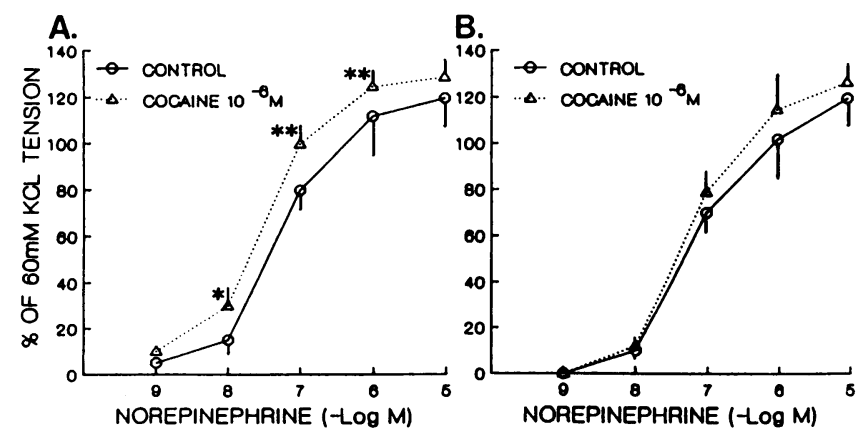

Figure 4. Norepinephrine dose-response relationship before (open circles-solid line) and after cocaine $10^{-6} \mathrm{M}$ (open triangles-dashed line) in control muscles $(A$ : left) versus muscles from animals pretreated with reserpine $\left(B\right.$ : right). ${ }^{*} P<0.05$ and ${ }^{* *} P<0.01$ vs. values before cocaine). ment. Thus, it appears reasonable to conclude that the $\left[\mathrm{Ca}^{++}\right]_{\mathrm{i}}$ mobilization during the cocaine-induced contraction is mediated by alpha- 1 adrenoceptors rather than by nonspecific diffusion of the $\mathrm{Ca}^{++}$into the cytoplasm. We have previously reported that alpha-1 adrenoceptor activation produced a transient increase in the $\left[\mathrm{Ca}^{++}\right]_{\mathrm{i}}$ level during force development followed by a lower plateau level during the period of force maintenance in ferret vascular smooth muscle $(18,19,37)$. The absence of the initial $\mathrm{Ca}^{++}$transient during cocaine-induced contraction may be explained as follows: first, the intensity of alpha adrenoceptor activation exerted by cocaine was less than maximal, because the amplitude of the cocaine-induced contraction was $\sim 50 \%$ of the response to $10^{-5} \mathrm{M}$ norepinephrine in our study. Ruzycky and Morgan (37) have recently shown that the transient $\left[\mathrm{Ca}^{++}\right]_{i}$ spike associated with phenylephrineinduced contractions was most pronounced at the maximally effective concentrations of this agonist; and second, local anesthetic agents like cocaine are known to affect $\left[\mathrm{Ca}^{++}\right]_{i}$ handling by the sarcolemma $(38,39)$ and sarcoplasmic reticulum $(40$, 41); these actions might modify $\left[\mathrm{Ca}^{++}\right]_{\mathrm{i}}$.

The mechanism by which cocaine decreases tension from the previous elevated level (i.e., relaxation) has not been extensively studied. According to experiments in other organs, cellular actions of local anesthetic agents like cocaine involve $(a)$ reduction of the rate of rise and amplitude of the action poten-

Table IV. Relationship of Force and Aequorin Luminescence after Cumulative Addition of Cocaine $(n=7)$

\begin{tabular}{lcccc}
\hline & & \multicolumn{3}{c}{ Cocaine (M) } \\
\cline { 3 - 5 } & Control & $10^{-4}$ & $10^{-3}$ & $3 \times 10^{-3}$ \\
\hline Force $\left(\mathrm{g} / \mathrm{mm}^{2}\right)$ & $3.0 \pm 0.5$ & $5.2 \pm 1.3^{*}$ & $4.8 \pm 1.2^{*}$ & $3.4 \pm 0.6$ \\
Light $(n A)$ & $1.8 \pm 0.4$ & $2.7 \pm 0.2^{*}$ & $2.6 \pm 0.2^{*}$ & $2.8 \pm 0.3^{*}$
\end{tabular}

Data are presented as mean \pm SEM. ${ }^{*} P<0.01$ vs. control condition. 
Table V. Effects of Electrical Transmural Stimulation on Contractile Responses of Muscles from Control Ferrets and from Reserpine Pretreated Ferrets

\begin{tabular}{lcccc}
\hline & \multicolumn{4}{c}{ Frequency $(\mathrm{Hz})$ of Stimulation (percentage of } \\
\cline { 2 - 5 } & 0.1 & 1.0 & 4.0 & 8.0 \\
\cline { 2 - 5 } & & & & \\
$\begin{array}{l}\text { Muscles from control ferrets } \\
\quad(n=8)\end{array}$ & $8 \pm 2$ & $38 \pm 6$ & $68 \pm 8$ & $74 \pm 8$ \\
$\begin{array}{c}\text { Before cocaine } \\
\text { After cocaine }\end{array}$ & $16 \pm 2^{*}$ & $78 \pm 10^{\ddagger}$ & $80 \pm 14^{\ddagger}$ & $82 \pm 12$ \\
$\begin{array}{l}\text { Muscles from reserpine } \\
\text { pretreated ferrets }(n=6)\end{array}$ & & & & \\
$\begin{array}{c}\text { Before cocaine } \\
\text { After cocaine }\end{array}$ & $0 \pm 1$ & $8 \pm 3$ & $18 \pm 6$ & $15 \pm 6$ \\
\hline
\end{tabular}

Data are presented as mean \pm SEM. ${ }^{*} P<0.05,{ }^{\ddagger} P<0.01$ vs. before cocaine.

tial with no appreciable change in resting membrane potentials $(38,39,42) ;(b)$ reduction in ion influx across the sarcolemma $(38,39)$; and $(c)$ decrease in $\mathrm{Ca}^{++}$release and/or extrusion by the sarcoplasmic reticulum $(40,43,44)$. If a decrease in tension induced by high concentrations of cocaine is due to any of these effects, $\left[\mathrm{Ca}^{++}\right]_{\mathrm{i}}$ will decline in parallel with tension. In this study, however, $\left[\mathrm{Ca}^{++}\right]_{\mathrm{i}}$ remained elevated despite a decrease in tension. Therefore, it is clear that the mechanism of cocaine-induced decrease in tension cannot be explained by any of the possible mechanisms mentioned above. Alternatively, it appears reasonable to propose that the $\mathrm{Ca}^{++}$sensitivity of the contractile proteins or myofilaments decreased after cocaine. Since preliminary studies indicated that cocaine in concentrations $\geq 10^{-3} \mathrm{M}$ suppresses the $\mathrm{Ca}^{++}$-aequorin luminescence relationship, it was difficult to pursue the subcellular mechanism of the $\left[\mathrm{Ca}^{++}\right]_{\mathrm{i}}$ changes during the cocaine-induced tension decrease. Although Kuriyama and Suyama (16) reported that the $\mathrm{Ca}^{++}$-force relationship was unchanged by cocaine $10^{-4} \mathrm{M}$ in saponin skinned guinea pig mesenteric artery, the concentrations employed by these investigators were lower than those causing vasorelaxation in this study. A recent study from our laboratory has shown that negative inotropic actions of cocaine in myocardial tissues correlate with $\left[\mathrm{Ca}^{++}\right]_{i}$ levels (45). Thus, the mechanisms by which high concentrations of cocaine reduces contractile force may differ between cardiac and smooth muscles.

Provided that cocaine-induced supersensitivity to norepinephrine is due solely to cocaine's action on adrenergic nerve endings, it will be lost when the amount of catecholamine in the nerve endings is decreased. This study shows that muscles from ferrets that have undergone reserpine pretreatment failed to respond to tyramine (Table I), and that cocaine did not induce supersensitivity to norepinephrine or adrenergic nerve stimulation (Fig. 4) in muscles from ferrets that underwent reserpine pretreatment. Therefore, we may conclude that cocaine-induced supersensitivity to exogenous and endogenous norepinephrine was presumably produced by its action on the adrenergic nerve endings. These results may confirm a study by Webb et al. (13) that cocaine-induced supersensitivity to norepinephrine did not occur after pretreatment with 6-hydroxydopamine.
These findings are strengthened by clinical reports that human coronary arteries respond to alpha adrenoceptor stimulation by constriction $(46,47)$. Moreover, cocaine concentrations that caused contraction of aortic smooth muscles of the ferret $\left(10^{-6} \mathrm{M}\right.$ to $\left.10^{-4} \mathrm{M}\right)$ were fairly comparable with the plasma concentrations reported in cocaine abusers and in cocaine-related deaths. Plasma cocaine levels in those patients is reported to be $0.2-100 \mu \mathrm{g} / \mathrm{ml}\left(6 \times 10^{-7}\right.$ to $\left.3 \times 10^{-4} \mathrm{M}\right)(48-50)$. However, there are obvious difficulties in comparing the results of our study with clinical reports of cocaine-induced cardiovascular events, because there appear to be marked differences among vascular beds of various species in regard to their responsiveness to cocaine (5). This is due to differences in receptor types and density among vascular tissues from different species. Despite these limitations, we believe that this study sheds light on the mechanisms underlying cocaine-induced changes in vascular tone and provides experimental clues that at least partially elucidate the pathophysiology of cocaine-related cardiovascular complications.

\section{Acknowledgments}

The authors express their appreciation to Dr. William Grossman for his encouragement of this work and Mr. Jason Kravitz for typing this manuscript.

This study was supported in part by grants DA-05171 from the National Institute of Drug Abuse, and HL-31117, HL-31704, and HL01611 from the National Institutes of Health, and a Grant-in-Aid from the Mochida Memorial Foundation for Medical and Pharmaceutical Research.

\section{References}

1. Gawin, F. H., and E. H. Ellinwood. 1988. Cocaine and other stimulants. Actions, abuse and treatment. N. Engl. J. Med. 318:1173-1182.

2. Smith, H. W. B., H. A. Liberman, S. L. Brody, L. L. Battey, B. C. Donahue, and D. C. Morris. 1987. Acute myocardial infarction temporally related to cocaine use. Ann. Int. Med. 107:13-18.

3. Isner, J. M., N. A. M. Estes, P. D. Thompson, M. R. Costanzo-Nordin, R. Subramanian, G. Miller, G. Katsas, K. Sweeney, and W. Q. Sturner. 1986. Acute cardiac events temporally related to cocaine abuse. N. Engl. J. Med. 315:14381443.

4. Levine, S. R., and K. M. A. Welch. 1987. Cocaine and stroke. Curr. Concepts of Cerebrovasc. Dis. Stroke. 22:25-30.

5. Cregler, L. L., and H. Mark. 1986. Medical complications of cocaine abuse N. Engl. J. Med. 315:1495-1500.

6. Schachne, J. S., B. H. Roberts, and P. D. Thompson. 1984. Coronary artery spasm and myocardial infarction associated with cocaine use. $N$. Engl. J. Med. 310:1665-1666.

7. Zimmerman, F. H., G. M. Gustafson, and H. G. Kemp. 1987. Recurrent myocardial infarction associated with cocaine abuse in a young man with normal coronary arteries: evidence for coronary artery spasm culminating in thrombosis. J. Am. Coll. Cardiol. 9:964-968.

8. Simpson, R. W., and W. D. Edwards. 1986. Pathogenesis of cocaine-induced ischemic heart disease. Arch. Pathol. Lab. Med. 110:479-484.

9. Ritchie, J. M., and N. M. Greene. 1985. Local anesthetics. In Goodman and Gilman's The Pharmacologic Basis of Therapeutics. A. G. Gilman et al., editors. Macmillian Publishing Co., New York. 302-321.

10. Whitby, L. G., G. Hertting, and J. Axelrod. 1960. Effect of cocaine on the disposition of noradrenaline labelled with tritium. Nature (Lond.). 187:604-605.

11. Trendelenburg, U. 1959. The supersensitivity caused by cocaine. J. Pharmacol. Exp. Ther. 125:55-65.

12. Webb, R. C., and P. M. Vanhoutte. 1982. Cocaine-induced release of noradrenaline in rat tail artery. J. Pharm. Pharmacol. 34:134-136.

13. Webb, R. C., P. M. Vanhoutte, and D. F. Bohr. 1980. Inactivation of released norepinephrine in rat tail artery by neuronal uptake. J. Cardiovasc. Pharmac. 2:121-132.

14. Wilkerson, R. D. 1989. Cardiovascular effects of cocaine: enhancement by yohinbine and atropine. J. Pharmacol. Exp. Therap. 248:57-61.

15. Pierre, A., W. Kossowsky, S. T. Chou, and A. R. Abadir. 1985. Coronary 
and systemic hemodynamics after intravenous cocaine injection. Anesthesiology 63:28a. (Abstr.)

16. Kuriyama, H., and A. Suyama. 1983. Multiple actions of cocaine on neuromuscular transmission and smooth muscle cells of the guinea pig mesenteric artery. J. Physiol. (Lond.). 337:631-654.

17. Stewart, D. M., W. P. Rogers, J. E. Mahaffey, S. Witherspoon, and E. F. Woods. 1963. Effects of local anesthetics on the cardiovascular system in dog. Anesthesiology. 24:620-628.

18. Morgan, J. P., and K. G. Morgan. 1982. Vascular smooth muscle: the first recorded Ca ${ }^{2+}$ transients. Pflügers Arch. 395:75-77.

19. Morgan, J. P., and K. G. Morgan. 1984. Stimulus-specific patterns of intracellular calcium levels in smooth muscle of the ferret portal vein. J. Physiol. (Lond.). 351:155-167.

20. Bradley, A. B., and K. G. Morgan. 1987. Alterations in cytoplasmic calcium sensitivity during porcine coronary artery contractions as detected by aequorin. J. Physiol. (Lond.). 385:437-448.

21. Jiang, M. J., and K. G. Morgan. 1987. Intracellular calcium levels phorbol ester-induced contractions of vascular smooth muscle. Am. J. Physiol. 253:H1365-H1371.

22. Weiner, N. 1985. Drugs that inhibit adrenergic nerves and block adrenergic receptors. In The Pharmacological Basis of Therapeutics. A. G. Gibman et al., editors. Macmillan Publishing Co., New York. 145-180.

23. Barnes, J. M., N. M. Barnes, B. Costall, R. J. Naylor, and F. D. Tattersall. 1988. Reserpine, para-chlorophenylalanine and fenfluramine antagonize cisplatin-induced emesis in the ferret. Neuropharmacol. 783-790.

24. Grassby, P. F., and J. Broadley. 1986. Responses mediated via beta-1 adrenoceptors but not beta-2 adrenoceptors exhibit supersensitivity after chronic reserpine pretreatment. J. Pharmacol. Exp. Ther. 237:950-951.

25. Lee, T. J. F., D. P. Westfall, and W. W. Fleming. 1975. The correlation between spontaneous contractions and postjunctional supersensitivity of the smooth muscle of the rat vas deferens. J. Pharmacol. Exp. Ther. 136-148.

26. Langer, S. Z., P. R. Draskoczy, and U. Trendelenburg. 1967. Time course of the development of supersensitivity to various amines in the nictitating membrane of the pithed cat after denervation or decentralization. J. Pharmacol. Exp. Ther. 255-273.

27. Fleming, W., and D. P. Westfall. 1988. Adaptive super-sensitivity. In Catecholamines I. U. Trendelenburg, and N. Weiner, editors. Springer-Verlag, Berlin. 509-559.

28. Allen, D. G., and J. R. Blinks. 1979. The interpretation of light signals from aequorin-injected skeletal and cardiac muscle cells: a new method of calibration. In Detection and Measurement of Free $\mathrm{Ca}^{2+}$ in Cells. C. C. Ashley, and A. K. Campbell, editors. Elsevier Science Publishers B. V., Amsterdam. 159-174.

29. Delean, A., P. J. Manson, and D. Rodbard. 1978. Simultaneous analysis of families of sigmoidal curves. Application to bioassay, redioligand assay, and physiological dose-response curves. Am. J. Physiol. 235:E97-E102.

30. Catchelove, R. F. 1972. Influence of $\mathrm{CO}_{2}$ and pH on local anesthetic actions. J. Pharmacol. Exp. Ther. 181:298-309.

31. Vanhoutte, P. M., G. M. Rubanyi, V. M. Miller, and D. S. Houston. 1986 Modulation of vascular smooth muscle contraction by the endothelium. Ann. Rev. Physiol. 48:307-320.

32. Rongione, A. J., G. Steg, D. Gal, and J. M. Isner. 1988. Cocaine causes endothelium-independent constriction of vascular smooth muscle. Circulation 78:II-436.

33. Shibata, S., K. Hattori, I. Sakurai, J. Mori, and M. Fujiwara. 1971. Adrenergic innervation and cocaine-induced potentiation of adrenergic responses of aortic strips from young and old rabbits. J. Pharmacol. Exp. Ther. 177:621-632.

34. Greenberg, R., and I. R. Innes. 1976. The role of bound calcium in supersensitivity induced by cocaine. Br. J. Pharmacol. 57:329-334.

35. Maxwell, R. A., W. B. Wastilla, and S. B. Eckhardt. 1966. Some factors determining the response of rabbit aortic strips to di-norepinephrine-7- $\mathrm{H}^{3}$ hydrochloride and the influence of cocaine, guanethidine and methylphenidate on these factors. J. Pharmacol. Exp. Ther. 151:253-261.

36. Innes, I. R., and R. Mailhot. 1973. Effect of cocaine on the affinity of $\alpha$-adrenoceptor noradrenaline. Br. J. Pharmacol. 48:139-143.

37. Ruzycky, A. L., and K. G. Morgan. 1989. Involvement of the protein kinase $\mathrm{C}$ system in calcium-force relationships in ferret aorta. Br. J. Pharmacol 97:391-400.

38. Davis, L. D., and J. V. Tomto. 1969. Electrophysiological actions of lidocaine on canine ventricular muscle and purkinic fibers. Circ. Res. 24:639-655.

39. Bigger, J. T., Jr., and W. J. Mandel. 1970. Effects of lidocaine on electrophysiological properties of ventricular muscle and purkinje fibers. J. Clin. Invest. 49:63-77.

40. Johnson, P. N., and G. Imes. 1969. Effect of methylxanthines and loca anesthetics on fragmented sarcoplasmic reticulum. J. Pharmacol. Exp. Ther. 169:308-314

41. Saida, K., and A. Suzuki. 1981. Mode of action of prilocaine on sarcoplasmic reticulum in skinned skeletal muscle fibers. J. Pharmac. Exp. Ther. 219:815820.

42. Przywara, D. A., and G. E. Dambach. 1989. Direct actions of cocaine on cardiac cellular electrical activity. Circ. Res. 65:185-192.

43. Blinks, J. R., C. B. Olson, and B. R. Jewell. 1972. Influence of caffeine and other methylxanthines on mechanical properties of isolated mammalian heart muscle. Evidence for a dual mechanism of action. Circ. Res. 30:367-392.

44. Yagi, S., and M. Endo. 1980. Effects of dibucaine on skinned skeletal muscle fibers. An example of multiple actions of a drug on a single subcellular structure. Biomedical Research. 1:269-272.

45. Perreault, C. L., P. D. Allen, K. G. Morgan, and J. P. Morgan. 1989. Differential mechanisms of cocaine-induced depression of contractile function in cardiac versus vascular smooth muscle. Circulation. 80(Suppl): 15 .

46. Mudge, G. H., W. Grossman, R. M. Mills, and E. Braunwald. 1976. Reflex increase in coronary vascular resistance in patients with ischemic heart disease. N. Engl. J. Med. 295:1333-1337.

47. Brown, E. G., A. B. Lee, E. L. Bolson, and H. T. Dodge. 1984. Reflex constriction of significant coronary stenosis as a mechanism contributing to ischemic left ventricular dysfunction during isometric exercise. Circulation. 70:18 24.

48. Poklis, A., M. A. Mackell, and M. Graham. 1985. Disposition of cocaine in fatal poisoning in man. J. Anal. Toxicol. 9:227-229.

49. Van Dyke, C., P. G. Barash, P. Jatlow, and R. Byck. 1976. Cocaine: plasma concentrations after intranasal application in man. Science (Wash. DC) 191:859-61.

50. Winek, C. L., W. W. Wahba, L. Rozin, and J. K. Jannsen. 1987. An unusually high blood cocaine concentration in a fatal case. J. Anal. Toxicol. 11:43-46. 